\title{
BIMBINGAN KELOMPOK DENGAN MEDIA FILM (STUDI KASUS : PENDIDIKAN SEKS PADA SISWA KELAS X SMAN 15 DI SURABAYA)
}

\author{
Ayu Alivia Aufar ${ }^{1}$, Aniek Wirastania ${ }^{2}$ \\ Universitas PGRI Adi Buana Surabaya \\ Email : ayuaufar322@gmail.com
}

\begin{abstract}
Tujuan melakukan penelitian ini untuk menguji kefektifan teknik cinematherapy di dalam pemberian layanan konseling bimbingan kelompok terhadap pendidikan seks siswa kelas X di SMAN 15 Surabaya. Rancangan penelitian yang digunakan dalam penelitian ini menggunakan one group pre-test post-test design yang diberikan pada 7 siswa kelas X dengan kategori skor pendidikan seks yang rendah. Metode penelitian ini menggunakan metode penelitian kuantitatif. Skala pengukuran yang digunakan didalam pengukuran instrument adalah pendidikan seks. Melihat fenomena yang terjadi saat ini, menjadi alasan peneliti untuk melakukan penelitian tentang rendahnya pendidikan seks yang ada di negara kita. Peneliti memilih SMAN 15 Surabaya sebagai tempat penelitiannya. Peneliti menggunakan teknik analisis data non parametric dan dengan uji Wilcoxon. Hasil interpretasi data yang menggunakan uji Wilcoxon diketahui Asymp. Sig (2-tailed) brnilai 0,018. Nilai 0,018<0,05, maka bisa disimpulkan bahwa Ho dapat diterima. Terdapat pengaruh yang signifikan di dalam layanan bimbingan kelompok dengan menggunakan teknik cinematherapy terhadap pendidikan seks siswa kelas X di SMAN 15 Surabaya.
\end{abstract}

Kata Kunci : Pendidikan Seks, Cinematherapy, Bimbingan Kelompok

Received : 2021-04-16. Published : 2021-08-31.

This is an open access article distributed under the terms of the Creative Commons Attribution 4.0 International License

Website: http://ejournal.umpri.ac.id/index.php/fokus

\section{PENDAHULUAN}

Diera milenial saat ini peradaban teknologi komunikasi dan informasi terus berkembang secara pesat sehingga ikut serta mengubah budaya masyarakat serta lingkungannya. Maka generasi milineal (usia muda) cenderung melakukan hal terupdate, dinamis untuk menunjukkan eksistensinya di era kekinian. Sehingga tidak dapat dipungkiri, dinamika kehidupan global mempengaruhi secara langsung terhadap eksistensi kaum muda di era milineal saat ini. Nilai-nilai budaya saat ini akan bergeraksecara dinamis mengikuti problematika maraknya pernikahan dini. Di Indonesia masih banyak terjadi pernikahan dini. Berdasarkan data Bada Pusat Statistik (BPS), Deputi Mentrei PPPA Bidang Tumbuh Kembang Anak yakni Lenny N. Rosalin, SE., M.Sc., Mfin, menyampaikan bahwasannya perempuan yang berusia 20-24 tahun telah berstatus kawin saat umur 18 tahun. Kalimantan Selatan menjadi wilayah tertinggi di Indonesia mengenai perempuan yang menikah pada saat usia dini, sebanyak $21,2 \%$, dan daerah yang paling rendah presentasenya yakni Sulawesi Tengah sebanyak 16,3\% menurut data BPS tahun 2019. Data tersebut diambil berdasarkan 
survey yang dilakukan. Karena kurangnya pengetahuan tentang seks usia dini yang sering dianggap tabu dan kurangnya pengawasan dari orang tua.

Di Indonesia mengalami peningkatan setiap tahun mengenai kasus seks pranikah yang dialami oleh remaja. Remaja Indonesia berusia 15-24 tahun melakukan seks pranikah mengalami peningkatan dari 5\% ke 8\% untuk laki-laki dan konstan 1\% untuk perempuan, hasil survey demografi Kesehatan Indonesia dalam kurun waktu dua periode yang berbeda pada tahun 2002-2003 dan 2012 (Farisandy \& Surjaningrum, 2019). Menurut Setyaningsih pada tahun 2016 menjelaskan bahwa kegiatan seks merupakan salah satu aktivitas seksual dimana adanya kontak langsung antara penis dan vagina hingga terjadi penetrasi. Aktivitas tersebut terjadi oleh individu dengan individu lainnya tanpa adanya ikatan perkawinan (Hadiono, 2018). Banyak dampak negative yang diakibatkan setelah melakukan seks pranikah diantaranya fisik, psikologis, maupun kehidupan sosial pelaku. Dampak negatif segi fisiologis, pelaku dapat mengalami hamil pranikah, melakukan tindak aborsi ilegal, hingga penyakit menular seksual. Menurut Ahadiyah tahun 2019 terdapat dampak negative segi psikologis, pelaku akan mengalami penyesalan, perasaan berdosa yang berkepanjangan, mengalami stress hingga depresi, dikarenakan perilaku yang sebenarnya tidak diharapkan. Remaja melakukan perilaku seks pranikah memiliki beberapa alasan. Studi cross-sectional yang telah dilakukan oleh Asamoah dan Argardh (2018), individu dengan rentang usia 18-29 tahun di Sweden (Farisandy \& Surjaningrum, 2019). Asamoah dan Argardh (2018) melakukan studi cross-sectional pada individu dengan rentang usia 18-29 tahun di Sweden menghasilkan bahwa pelaku seks pranikah melakukannya dengan alasan mencari sensasi, dan kurangnya peran keluarga, seperti keadaan keluarga yang tidak stabil, ekonomi rendah atau individu yang berkembang di antara lingkungan orangtua yang berpendidikan rendah dan lingkungan yang rusak. Beberapa factor tersebut menjadi alas an individu melakukan seks pranikah.

Sebagian aspek dibalik alibi orang tua kurang dalam mengenalkan pembelajaran seks pada anak, diantaranya pengetahuan orang tua yang terbatas tentang reproduksi anak muda, perasaan malu untuk bertanya sesuatu hal yang tabu, serta anggapan orang tua tentang norma konservatif mengenai pembelajaran hal seksualitas kian menjadi tabu. Orang tua menyangka kalau pembelajaran seksualitas sangat vulgar untuk diberikan kepada anak. Kekhawatiran orangtua akan perilaku anaknya ketika diberikan pengetahuan seksual yang membuatnya mencari tahu halhal seksualitas (Amaliyah, 2017). Bagi (Lubis, 2016) mengatakan kalau pembelajaran seksualitas ialah salah satu metode untuk mengurangi perilaku seks pranikah, pemerkosaan, kehamilan pranikah, aborsi, dan penularan penyakit seks yang menular. Bagi (Amaliyah, 2017) menarangkan kalau pembelajaran seksualitas bisa kurangi data menimpa seksualitas yang galat, tingkatkan pengetahuan seksualitas yang pas, memantapkan nilai serta perilaku yang positif, dan tingkatkan keahlian orang dalam mengambil keputusan. Anak muda pula bisa menghindarkan serta ataupun menunda ikatan intim, merendahkan frekuensi sikap intim yang tidak nyaman, kurangi jumlah pendamping dalam melaksanakan kegiatan intim, dan tingkatkan perlindungan pada akibat seks yang tidak terkendali semacam kehamilan serta penyakit meluas.

Beberapa faktor tersebut terdapat peran penting secara keseluruhan bimbingan dan konseling di dalamnya, sebagaimana dinyatakan dalam American Counseling Association (ACA) menjelaskan bahwa bimbingan dan konseling dapat membantu siswa dalam menangani masalah emosi dan sosialnya, memahami hidup yang terarah, menciptakan iklim sekolah yang kondusif dan bagian yang penting untuk meningkatkan prestasi siswa. Keberhasilan layanan program bimbingan dan konseling dapat ditinjau dari kemajuan kemandirian siswa. Guru BK (Bimbingan Konseling) 
menjadi lebih terarah dan mudah dalam menggunakan strategi yang akan digunakan dalam permasalahan yang ada.

Konseling dilakukan dari manusia ke manusia lainnya. Berasal dari manusia, maksudnya pelayanan itu diselenggarakan bersumber pada hakikat keberadaan manusia dengan segenap ukuran kemanusiaannya. Diperuntukan buat manusia, dimaksudkan kalau pelayanan tersebut diselenggarakan demi tujuan- tujuan yang agung, mulia serta positif untuk kehidupan kemanusiaan mengarah manusia seutuhnya, baik manusia selaku orang ataupun kelompok. Dicoba oleh manusia dengan segenap derajat, martabat serta keunikan tiap- tiap yang ikut serta didalamnya. Layanan tutorial serta konseling ialah proses pemberian dorongan dan diberikan kepada siswa secara terus yang akan membantu siswa dalam mendapatkan solusi atas permasalahannya, sehingga siswa mampu memusatkan dirinya cocok dengan tuntutan serta kondisi area sekolah, keluarga serta warga. Menghindari dalam artian ini ialah menahan supaya suatu tidak terjalin. Sikap merupakan asumsi ataupun respon orang terhadap rangsangan ataupun area.

Kegiatan layanan di dalam bimbingan dan konseling, ada beberapa program layanan guna menunjang kebutuhan dan memfasilitasi siswa dalam dunia pendidikan. Beberapa jenis layanan bimbingan dan konseling yang dapat diberikan kepada siswa, diantaranya ada layanan informasi, bimbingan klasikal, kelompok, konseling individu, serta konseling kelompok. Beberapa jenis layanan yang bisa dipilih siswa untuk membantu dalam penyelesaian masalah. Guru BK merupakan konselor yang terdapat di sekolah. Tujuan pemberian layanan tutorial serta konseling merupakan buat menolong siswa keluar dari permasalahan, mengatur emosi serta mengalami kehidupan sosialnya. Layanan bimbingan dan konseling memberikan pengaruh penting sebelum dan sesudah siswa mendapatkannya. Guru BK akan menilai dan memantau perkembangan siswa, dari mulai awal sebelum diberikan layanan bimbingan dan konseling sampai pada tahap akhir setelah diberikannya layanan. Sering kali layanan ini digunakan untuk membantu permasalahan siswa dengan cara berdiskusi bersama teman anggota. Berawal dari menentukan kesepaktan pembahasan permasalahan, dengan memberikan treatment kepada siswa yang akan menghasilkan beberapa sudut pandang sebuah permasalahan dan siswa dapat memecahkan maslaah dengan sendirinya.

Masa Anak muda (Adolescence) saat sebelum menggapai masa anak muda, orang sudah hadapi serangkaian pertumbuhan serta mendapatkan banyak pengalaman. Tidak terdapat anak wanita ataupun anak pria yang merambah masa anak muda dalam wujud kosong, yang cuma mempunyai kode genetik yang hendak memastikan bermacam benak, perasaan, serta prilakunya. Melalui bimbingan kelompok, siswa dapat berpikir kritis dalam menghadapi sebuah permasalahan. Pada usia remaja, tentunya gejolak emosi serta sosial yang terus berkembang menjadikan siswa SMA sering kali mencoba hal baru yang ia kurang pahami. Anak jaman sekarang, jika hanya diberikan pembelajaran secara satu arah kurang dapat bisa diterima dan dipahamkan. Cara yang dipandang efektif oleh Guru BK adalah dengan memberikan layanan bimbingan kelompok dengan menggunakan teknik cinematherapy. Guru BK menyesuaikan strategi atau teknik dengan masalah serta pendekatan yang bisa diterima oleh siswa. seperti yang dilakukan oleh peneliti sebelumn ya, bahwa bimbingan kelompok dengan menggunakan teknik cinematherapy mempunyai efktivitas dalam menangani permasalahan siswa. menurut (Maharani, 2019) keefektivitasan penggunaan media film bertema pendidikan dalam layanan informasi bimbingan klasikal dimana trdapat perbedaan yang signifikan ketika sebelum menggunakan strategi tersebut dan sesudahnya. Maka dari itu, penelitian kali ini menggunakan cinematherapy untuk memberikan layanan bimbingan kelompok dalam pendidikan seks anak remaja. 
Bagi (Niva, 2016) cinematherapy merupakan metode terapeutik spesial yang di dalamnya memakai film komersial yang diseleksi buat memperoleh makna terapeutik pada konseli tentang pemikiran terhadap orang ataupun terhadap orang lain. Film menyajikan segmen yang bisa menjadikan kekuatan dalam menyelami pengalaman manusia. Cinematherapy menjadikan kekuatan itu selaku perlengkapan buat tingkatkan pemahaman manusia. Lewat cinematherapy, konseli akan belajar dan memandang fenomena yang terjadi di sekitarnya melalui pengetahuan yang baru. Alibi pemakaian cinematherapy ialah siswa bahagia menyaksikan film. Film tercantum ke dalam jenis audiovisual yang menyajikan tampilan foto gerak serta suara, foto gerak digunakan buat memicu siswa lewat indra penglihatan serta suara digunakan buat memicu siswa lewat indra rungu. Penggabungan indra penglihatan serta rungu diharapkan menjadikan siswa lebih gampang meresap data yang diberikan. Film sebagai media belajar siswa yang berupa audio visual disesuaikan dengan perkembangan zaman dan kebutuhan permasalahan siswa..

Melalui media film dapat menjadi media pembelajaran yang menyenangkan dan dapat diterima oleh siswa. siswa lebih dapat menerima dengan mudah belajar melalui audio visual. Film dapat digunakan dalam penggambaran permasalahan secara nyata yang bisa diaplikasikan ketika pembelajaran. Dampak dari melihat film dapat menstimulus kognitif siswa dan mampu berfikir kritis. Berkembangnya zaman dan teknologi, membuat film menjadi media dalam pembelajaran yang lebih dapat diterima oleh siswa. media belajar melalui film dapat menyesuaikan dengan kebutuhan siswa dan membantu kinerja Guru BK dalam memberikan layanan konseling kepada siswa. .

Berdasarkan observasi awal, ditemukan beberapa permasalahan diantaranya yaitu masalah remaja yang kurang berfikir kritis dalam menghadapi perkembangan zaman dan tingkatan siklus menjadi seorang remaja ke dewasa. Permasalahan terjadi karena kurangnya minat pada saat mengikuti pelajaran dan pengaruh zaman yang semakin berkembang dengan hal yang serba instan namun tidak memberikan efek apapun bagi siswa. Teknik cinematherapy menggunakan film yang sudah dipilih yakni "Dua Garis Biru" diharapkan mampu dalam menstimulus siswa untuk bisa berfikir kritis dan memahami, menganalisa, serta menerapkan hal yang menjadi contoh positif dalam film. Isi dari media film yang dipilih menggambarkan tentang kehidupan anak remaja yang melakukan kesalahan fatal dan wujud dari kurangnya pendidikan seks bagi anak remaja.

Film "Dua Garis Biru" ini terdapat banyak pesan serta contoh kehidupan langsung yang bisa diamati dan dianalisis oleh siswa. Film remaja yang memang dibuat untuk mengedukasi para siswa dan tentunya dengan pengawasan guru BK atau orangtua agar siswa dapat memahami dan mengambil pesan yang disampaikan. Setelah menggunakan media film tersebut, siswa bisa lebih menjadi waspada terhadap pergaulan bebas dan memiliki pengetahuan seks yang menjadi bekal dalam berkehidupan sosial dan tidak digunakan sebagai hal yang negatif. Peneliti berharap agar bisa membantu dalam menurunkan nilai survey angka anak remaja menikah usia dini karena kurangnya pengetahuan tentang seks. Sehingga dapat mengurangi kasus anak hamil diluar nikah dan menjadikan siswa dan remaja Indonesia sebagai generasi penerus yang dapat dibanggakan.

\section{METODE}

Satu set pre-test dan post-test adalah kelompok penelitian pra-eksperimen (Sumadi Suryabrata, 2014) Satu set desain penelitian pre-test dan post-test: T1 adalah teknik pengukuran variabel terikat sebelum menerima layanan bimbingan kelompok terapi film, T2 adalah Pengukuran variabel terikat setelah penggunaan teknologi terapi film untuk memberikan layanan bimbingan kelompok, Xt, yaitu penggunaan teknologi 
terapi film untuk memberikan layanan bimbingan kelompok. Gunakan teknik pengambilan sampel yang menarik untuk menentukan sampel. Pemilihan sampel didasarkan pada karakteristik yang telah ditentukan dan diketahui yang dibagikan kepada calon sampel dalam bentuk kuesioner. Alat kuesioner harus mengukur validitas dan reliabilitas data agar dapat menghasilkan data yang valid dan reliabel dalam penelitian. Instrumen yang efektif mengacu pada instrumen yang dapat digunakan untuk mengukur apa yang seharusnya diukur, sedangkan instrumen yang andal mengacu pada instrumen yang menghasilkan data yang sama ketika digunakan beberapa kali untuk mengukur objek yang sama.

Tabel 1. Penilaian Alternatif Jawaban Angket

\begin{tabular}{lccc}
\hline \multirow{2}{*}{ Jenis Pertanyaan } & \multicolumn{2}{c}{ Alternatif Jawaban } & \\
\cline { 2 - 4 } & Setuju & Ragu & Tidak Setuju \\
\hline $\begin{array}{l}\text { Favorable } \\
\text { (Pertanyaan positif) }\end{array}$ & 3 & 2 & 1 \\
\hline $\begin{array}{l}\text { Unfavorable } \\
\text { (Pertanyaan Negatif) }\end{array}$ & 1 & 2 & 3 \\
\hline
\end{tabular}

Tabel 2. Kisi-kisi Pengembangan Instrumen Penelitian

\begin{tabular}{|c|c|c|c|c|}
\hline \multirow{2}{*}{ Variabel } & \multirow{2}{*}{ Indikator } & \multirow{2}{*}{ Sub Indikator } & \multicolumn{2}{|c|}{ No Item } \\
\hline & & & + & - \\
\hline \multirow{4}{*}{$\begin{array}{l}\text { Pendidikan } \\
\text { Seks }\end{array}$} & $\begin{array}{l}\text { Sex } \\
\text { Knowledge }\end{array}$ & $\begin{array}{l}\text { a. Batasan Laki-Perempuan } \\
\text { b. Efek negatif seks usia dini }\end{array}$ & $1,9,17$ & $2,10,18$ \\
\hline & $\begin{array}{l}\text { Parent } \\
\text { Attention }\end{array}$ & $\begin{array}{l}\text { a. Kebebasan berteman } \\
\text { b. Lingkungan Keluarga }\end{array}$ & $4,12,19$ & $3,11,20$ \\
\hline & Emotional & $\begin{array}{l}\text { a. Tindakan } \\
\text { b. Persepsi }\end{array}$ & 5,13 & 6,14 \\
\hline & $\begin{array}{l}\text { Access Sex } \\
\text { Informatio } \\
n\end{array}$ & $\begin{array}{l}\text { a. IT atau Gadget } \\
\text { b. Lingkungan Sosial }\end{array}$ & 8,16 & 7,15 \\
\hline
\end{tabular}

\section{HASIL DAN PEMBAHASAN}

Berdasarkan rancangan intervensi yang telah dibuat diawali dengan pelaksanaan uji Pre-test di kelas X lalu dianalisis dan dikategorikan pada 3 kategori, yaitu kategori tinggi, kategori sedang, dan kategori rendah. Hasil data Pre-test menunjukkan bahwa terdapat 7 subjek penelitian yang memiliki pengetahuan pendidikan seks dengan kategori rendah.

Tabel 3. Hasil skor Pre-test pengetahuan pendidikan seks siswa kelas X 


\begin{tabular}{cccl}
\hline No & Nama siswa & $\sum$ y (Skor total) & Kategori \\
\hline 1 & AH & 28 & Rendah \\
\hline 2 & NS & 24 & Rendah \\
\hline 3 & DN & 26 & Rendah \\
\hline 4 & VP & 28 & Rendah \\
\hline 5 & RI & 25 & Rendah \\
\hline 6 & AW & 25 & Rendah \\
\hline 7 & HS & 28 & Rendah \\
\hline
\end{tabular}

Hasil Pre-test ini menunjukkan kondisi awal sebelum responden diberikan treatment. setelah diperoleh hasil Pre-test, responden yang memiliki hasil rendah termasuk dalam kategori subjek yang akan diteliti dan diberikan perlakuan untuk bimbingan kelompok. Menggunakan film "Dua Garis Biru" sebagai media, narasumber diberikan layanan konsultasi berupa bimbingan kelompok, yang bertujuan untuk mempengaruhi orang yang diwawancarai untuk meningkatkan kesadaran mereka tentang pendidikan seks. Setelah diketahui bahwa siswa yang memiliki skor rendah dalam Pendidikan seks, maka akan diberikan treatment teknik cinematherapy dalam layanan bimbingan kelompok untuk membantu dalam meningkatkan pengetahuan pendidikan seks. Pemberian treatment dilakukan secara enam kali secara daring dan luring.

Tabel 4. Hasil skor Post-test Pendidikan seks siswa kelas X

\begin{tabular}{llcl}
\hline No & Nama Siswa & $\sum$ y (Skor Total) & Kategori \\
\hline 1 & AH & 33 & Rendah \\
\hline 2 & NS & 34 & Sedang \\
\hline 3 & DN & 32 & Sedang \\
\hline 4 & VP & 32 & Sedang \\
\hline 5 & RI & 35 & Sedang \\
\hline 6 & AW & 44 & Sedang \\
\hline 7 & HS & 34 & Sedang \\
\hline
\end{tabular}

Tabel 4. menunjukkan hasil jumlah responden yang mengalami perubahan dalam pengetahuan Pendidikan seks setelah diberikan treatment. Hasil skor Post-test menunjukkan adanya peningkatan dari skor nilai yang sebelumnya rendah menjadi sedang, yaitu sejumlah 7 orang dengan skor $32-44$.

Berikut ini hasil Pre-test dan post-test Pendidikan seks siswa kelas X yang dapat dilihat dalam penjelasan pada tabel 5 . 
Tabel 5. Hasil skor Post-test Pendidikan seks siswa kelas X

\begin{tabular}{lllllll}
\hline No & $\begin{array}{c}\text { Nama } \\
\text { siswa }\end{array}$ & $\begin{array}{c}\text { Pre }^{-} \\
\text {test (x) }\end{array}$ & Kategori & $\begin{array}{c}\text { Post- } \\
\text { test (y) }\end{array}$ & Kategori & $\begin{array}{c}\text { Perbedaan } \\
\text { skor }\end{array}$ \\
\hline 1 & AH & 28 & Rendah & 33 & Sedang & 5 \\
\hline 2 & NS & 24 & Rendah & 34 & Sedang & 10 \\
\hline 3 & DN & 26 & Rendah & 32 & Sedang & 6 \\
\hline 4 & VP & 28 & Rendah & 32 & Sedang & 4 \\
\hline 5 & RI & 25 & Rendah & 35 & Sedang & 10 \\
\hline 6 & AW & 25 & Rendah & 44 & Sedang & 19 \\
\hline 7 & HS & 28 & Rendah & 34 & Sedang & 6 \\
\hline
\end{tabular}

Sedangkan hasil metode uji Wilcoxon Pendidikan seks pada siswa dapat dijelaskan sebagai berikut:

1. Peringkat negatif atau perbedaan negatif antara pendidikan seks pra-tes dan pascates. Terdapat 0 data negatif $(\mathrm{N})$, yang berarti pengetahuan pendidikan seks 7 siswa mengalami penurunan dari nilai pre-test dan post-test. Posisi rata-rata atau jumlah rata-rata tetes adalah 0 . Jumlah peringkat atau jumlah peringkat adalah 0 .

2. Positive rank atau selisih positif antara pendidikan seks untuk pre-test dan post-test. Terdapat 7 siswa mengalami peningkatan dalam pengetahuan pendidikan seks dari nilai pre-test dan post-test. Mean rank atau rata-rata peningkatan tersebut adalah 4.00, sedangkan jumlah rangking atau sum of ranks adalah 28. Dalam penelitian terjadi adanya peningkatan terhadap pendidikan seks.

3. Ties adalah kesamaan nilai pre-test dan post-test, disinilah nilai ties 0 , sehingga dapat dikatakan bahwa tidak ada nilai yang sama antara Pre-test dan post-test.

Diketahui asymp. Sig (2-tailed) bernilai -2,375. Angka tersebut lebih kecil dari 0,05. Dapat disimpulkan bahwa $\mathrm{H}_{0}$ dapat diterima. Artinya, teknik Cinematherapy dalam layanan bimbingan kelompok berpengaruh secara signifikan dapat memberikan pendidikan seks bagi siswa kelas X SMAN di Surabaya.

\section{SIMPULAN}

Berdasarkan data dari hasil analisis data penelitian, dapat disimpulkan bahwa berdasarkan hasil perhitungan yang dihasilkan, ada beberapa siswa yang mendapatkan skor rendah dan tinggi. Pada siswa yang mendapatkan skor rendah, setelahnya akan diberikan treatment sebanyak 6 kali guna memberikan layanan konseling berupa bimbingan kelompok via daring. Beberapa materi, sampai pada pembedahan script film "Dua Garis Biru" dilakukan dalam penyampaian pendidikan seks kepada siswa. Setelah dilakukan treatment selama 6 kali pertemuan secara daring, pada akhir pertemuan diberikan test lagi dan dievaluasi secara bersama untuk membahasnya. 


\section{DAFTAR PUSTAKA}

Ahadiyah, N. (2019). Bimbingan dan Konseling Islam dengan Terapi Rasional Emotif (REF) untuk menangani kecemasan seorang istri akibat suami selingkuh di Desa Manaruwi Bangil. Universitas Islam Negri Sunan Ampel Surabaya.

Amaliyah. S, N. (2017). Eksplorasi persepdi ibu tentang pendidikan seks untuk anak. Psympathic: Jurnal Ilmiah psikologi.

Asamoah, B. O., \& Agardh, A. (2018). Individual and family-level determinants of risky sexual behavior among swedish- and foreign-born young adults 18-30 years of age, residing in Skåne, Sweden. Arch Sex Behav, 4(2), 517 528. https://doi.org/10.1007/s10508-017-0978-5

Lubis, N. (2016). Psikologi Kespro. Wanita dan Perkembangan Reproduksinya. Ditinjau dari Aspek Fisik dan Psikologinya. Kencana.

Maharani, L. (2019). Efektivitas Penggunaan Media Film Bertema Pendidikan Dalam Layanan Informasi Bimbingan Kalsikal Untuk Meningkatkan Kemampuan Berpikir Kritis Siswa Kelas X SMA AL Muslim Tambun Bekasi. Jurnal Faktor UNINDRA.

Niva, H. (2016). Penerapan Pendekatan Cinematherapy untuk meningkatkan perilaku prososial pada siswa Bosowa International School Makassar. Jurnal Psikologi Pendidikan Dan Konseling. Jurnal Kajian Psikologi Pendidikan Dan Bimbingan Konseling.

Setyaningsih, E. (2016). Pengaruh Pendidikan Sebaya Terhadap Sikap Seks Pranikah Remaja Usia 15-19 Tahunb di RW 19 Kelurahan Jebres.

Suryabrata, Sumadi. 2014. Metodologi Penelitian Cetakan Ke 25. Jakarta : PT Rajagrafindo Persada. 